\title{
Determined to Die! Ability to Act Following Multiple Self-inflicted Gunshot Wounds to the Head. The Cook County Office of Medical Examiner Experience (2005-2012) and Review of Literature
}

\begin{abstract}
Cases of multiple (considered 2+) self-inflicted gunshot wounds are a rarity and require careful examination of the scene of occurrence; thorough consideration of the decedent's psychiatric, medical, and social histories; and accurate postmortem documentation of the gunshot wounds. We present a series of four cases of multiple self-inflicted gunshot wounds to the head from the Cook County Medical Examiner's Office between 2005 and 2012 including the first case report of suicide involving eight gunshot wounds to the head. In addition, a review of the literature concerning multiple self-inflicted gunshot wounds to the head is performed. The majority of reported cases document two gunshot entrance wound defects. Temporal regions are the most common affected regions (especially the right and left temples). Determining the capability to act following a gunshot wound to the head is necessary in crime scene reconstruction and in differentiation between homicide and suicide.
\end{abstract}

KEYWORDS: forensic science, multiple gunshot wounds to the head, suicide, ability to act, firearms, homicide

Penetrating gunshot wounds to the head usually result in immediate incapacitation of the victim as a consequence of enhanced intracranial tissue disruption. However, rarely more than one shot is necessary to have the fatal effects and the victim might pull the trigger several times, preserving consciousness after the first shot. When the decedent's body on the crime scene shows multiple gunshot wounds to the head, the case is often regarded as a homicide, resulting in a misinterpretation in the dynamic reconstruction. Conversely, several cases of suicide involving multiple gunshot wounds to the head have been reported in the forensic literature, showing the ability to act of the victim after two or more shots. These cases must be kept in mind to prevent incorrect conclusions.

The following text describes a case series from the Cook County Medical Examiner's Office between 2005 and 2012 concerning multiple self-inflicted gunshot wounds to the head, including a unique case of multiple suicidal gunshot wounds to the head in which the victim was able to shoot himself eight times, yet preserving his consciousness.

${ }^{1}$ Cook County Medical Examiner's Office, 2121 West Harrison Street, Chicago, IL 60612.

${ }^{2}$ Department of Anatomy, Histology, Forensic Medicine and Orthopedics, "Sapienza" University of Rome, Viale Regina Elena, 336 Rome, Italy.

Received 16 May 2014; and in revised form 4 Aug. 2014; accepted 14 Aug. 2014.

\section{Materials and Methods}

The files of the Cook County of Medical Examiner's Office in Chicago were searched for deaths due to self-inflicted gunshot wounds to the head between 2005 and 2012. We selected only the cases in which the injuries were located on the face and/or the head. The investigative report, the reports of the postmortem examinations and postmortem toxicological studies, was reviewed in each case. All of the cases had been investigated by a forensic pathologist from the Cook County Medical Examiner's Office, and a complete autopsy was performed on the body of each decedent. The investigative reports were reviewed for information concerning the circumstances of death. The autopsy reports were reviewed for external injuries, internal injuries, nature of injuries, and cause of death. The toxicological reports were reviewed for the presence of drugs or alcohol. In one case, a 3D reconstruction of the dynamics using the MacOSX ${ }^{\circledR}$ software (Apple, Cupertino, CA) "Poser Pro ${ }^{\circledR} 2014$ " was performed.

In addition, we also performed a review of the forensic literature concerning multiple suicidal gunshot wounds to the head, from 1860 to present.

\section{Results}

Four cases of multiple self-inflicted gunshot wounds to the head were identified from our review of the files in the Cook County Medical Examiner's Office from 2005 to 2012. These four cases will be presented with regard to the circumstances of 
the death, the nature of the external and internal injuries, and the wound course. One of the reports (Case 1) is a unique case of multiple suicidal gunshot wounds in which the victim was able to shoot himself eight times to his head preserving his consciousness, resulting in the case with the greatest number of self-inflicted gunshot wounds to the head ever reported in the published literature worldwide. This case will be discussed in detail. A summary of all cases is shown in Table 1.

\section{Case 1}

A 56-year-old Black man was found on the floor of his residence with multiple gunshot wounds to the head. The subject was taken by the paramedics to a hospital, where he died c. $22 \mathrm{~h}$ later. At the scene, a six-shot, .22 short caliber ROHM RG7 revolver was recovered under the subject's body and the subject's blood was present on a lockbox in the residence that contained firearm ammunition. According to the wife, the subject had a medical history of depression, had been threatening to kill himself for several days, and had recently been diagnosed with a lymphoma. Their house was recently found to need an estimated $\$ 30000.00$ foundation repair work. Postmortem examination of the body revealed eight entrance gunshot wounds on the decedent's head. There was no evidence of close-range firing (i.e., soot deposition or gunpowder stippling) surrounding any of the entrance defects. Two of the gunshots penetrated the skull causing injury to the brain (Fig. 1). On the right side of the head, there was a circular gunshot wound of entrance (GSW \#1), 0.1 inch in diameter. A ring of abrasion was present around the wound and an adjacent purple bruise was present. The wound course involved the right temporal bone, the right temporal lobe of the brain, and the cerebellum of the brain. Finally, a deformed lead bullet was recovered from the brain. The wound had caused a right subdural hematoma, composed of clotted blood, 0.1 inch thick, over the right cerebral hemisphere (Fig. 2). Diffuse subarachnoid hemorrhage was present. The wound coursed from right to left. Examination of the skin around the gunshot wound of entrance revealed no evidence of close-range firing. On the right side of the back of the head, there was a circular gunshot wound of entrance (GSW \#2), 0.1 inch in diameter. A ring of abrasion was present around the wound. The wound course involved the right parietal bone of the skull, the right parietal lobe of the brain, and the frontal sinus on the right side. Finally, multiple bullet fragments were present in the frontal sinus area of the facial skeleton that could not be recovered. Examination of the skin around the gunshot wound of entrance revealed no evidence of close-range firing. The wound caused a right subdural hematoma, composed of clotted blood, 0.1 inch thick over the right cerebral hemisphere. Diffuse subarachnoid hemorrhage on the right hemisphere and on the base of the brain was present. The remaining gunshots were associated with fragmented bullets recovered in the scalp adjacent to the skull (Fig. 3). The location and the features of the remaining gunshot wounds are shown in Table 2. According to the all the available features, they were consistent with a right-handed subject. A 3D graphic reconstruction was performed to clarify the event, with special regard to the shooting dynamics (Fig. 4). The ability of the subject to act was preserved, as he survived for $c .22 \mathrm{~h}$. Toxicological analyses were negative for alcohol, opiates, and cocaine.

\section{Case 2}

A 49-year-old White man was found unresponsive in the basement of his residence, in a supine position. A stainless steel, Smith and Wesson, 357 magnum revolver was lying between his left arm and his body. The gun barrel was facing down. Two spent casings were found and one was found behind the hammer. The subject had a history of depression since when he lost his job. No suicide note was found. On examination of the body, slightly beneath the chin (GSW \#1), there was a contact lacerated circular-shaped gunshot wound of entrance, 0.4 inches in diameter. Surrounding the entrance wound, there was a muzzle imprint. Soot deposition was found on the margins and in the underlying tissues. The wound upwards through the chin, fracturing the mandible, lacerating the lower inner lip, lacerating the tongue, passing through the maxilla, and the nasal skeleton. Finally, a deformed lead bullet was recovered from the subcutaneous tissue beneath the eyebrows. On the right side of the head in the parietal region (GSW \#2), there was a contact lacerated oval-shaped gunshot wound of entrance, 0.4 by 0.3 inches, with soot deposition. There was a muzzle imprint surrounded the injury. The bullet penetrated the right parietal bone, involved the right parietal lobe of the brain and the basal ganglia, and finally stopped at the left parietal bone of the skull, where two bullet fragments were recovered. Toxicological analyses were negative. The ability of the subject to act was preserved after the first shot. The subject was pronounced at the scene.

\section{Case 3}

A 64-year-old White man was found unresponsive lying on the rear deck of his home. A large amount of blood was observed at the scene. Two handguns (unspecified blue steel revolver and chrome steel revolver) were found at the scene, one near his feet and the other in proximity to this head. It was noted that the subject's home was "For sale," and the subject had not been seen in the area for several months. No suicide note was found. On examination of the body, on the right side

TABLE 1-Cases of suicide by multiple GSWS to the head reported in the Cook County Office of Medical Examiner between 2005 and 2013.

No. of GSW

to the Head Firearms

Entrance Wounds

Additional Features

Suicide Note

.22 ROHM revolver

Right temple; right parietal bone (penetrating wounds)

2

Smith and Wesson, 357 magnum revolver

2

Unspecified blue steel revolver and chrome steel revolver
Beneath the chin; right parietal region

Right temple; roof of the mouth and hard palate.

Right temple; submental region at the midline
History of depression. Recent foundation $\mathrm{N}$ repair estimate of $\$ 30000.00$ and a diagnosis of lymphoma. Survived for $c .22 \mathrm{~h}$.

Victim had lost his job. History of depression

Victim was in the process of a divorce and his home was "For Sale"

He stated he was going to kill himself due to the "excessive pain" following a prostate surgery 


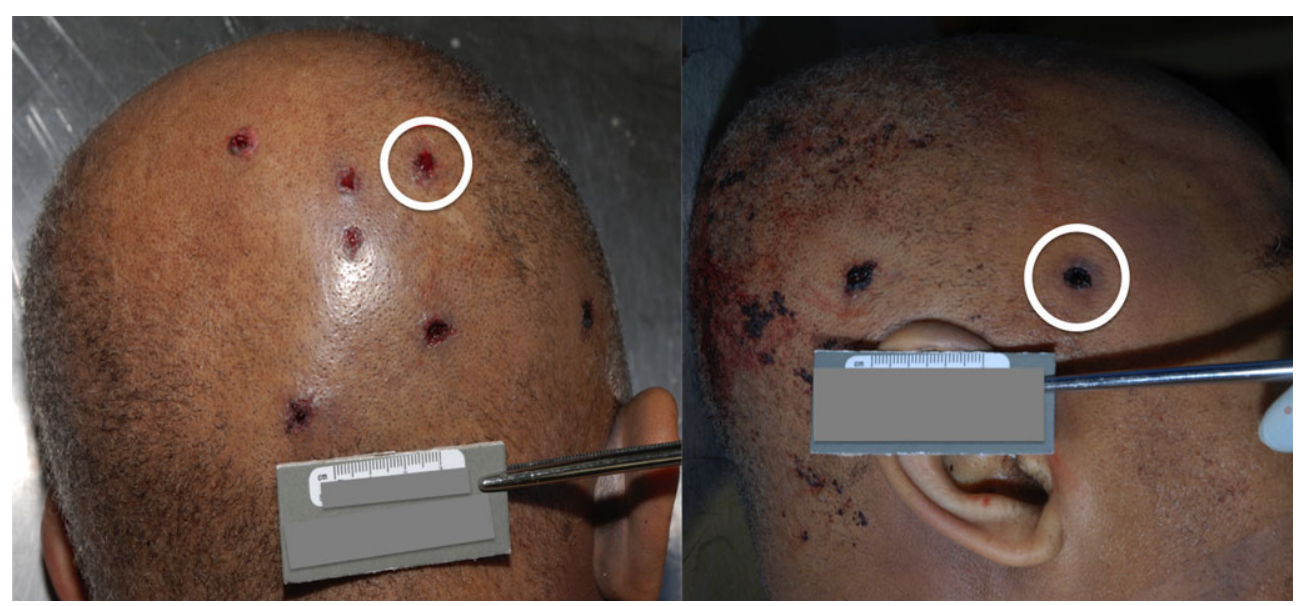

FIG. 1-Gunshot wounds of entrance to the head. The penetrating wounds are circled in white.

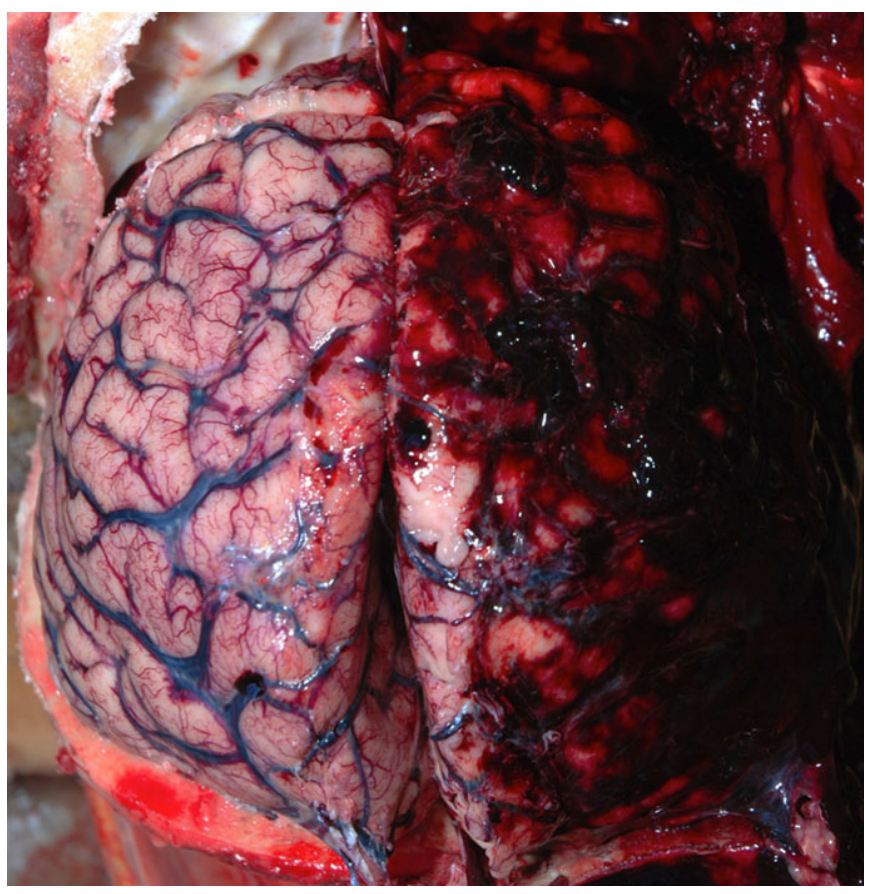

FIG. 2-Injury to the right cerebral hemisphere.

of the head (GSW \#1) there was a gunshot wound of entrance located. The wound measured 0.3 inches in diameter and was surrounded by a concentric abraded margin measuring 0.2 inches

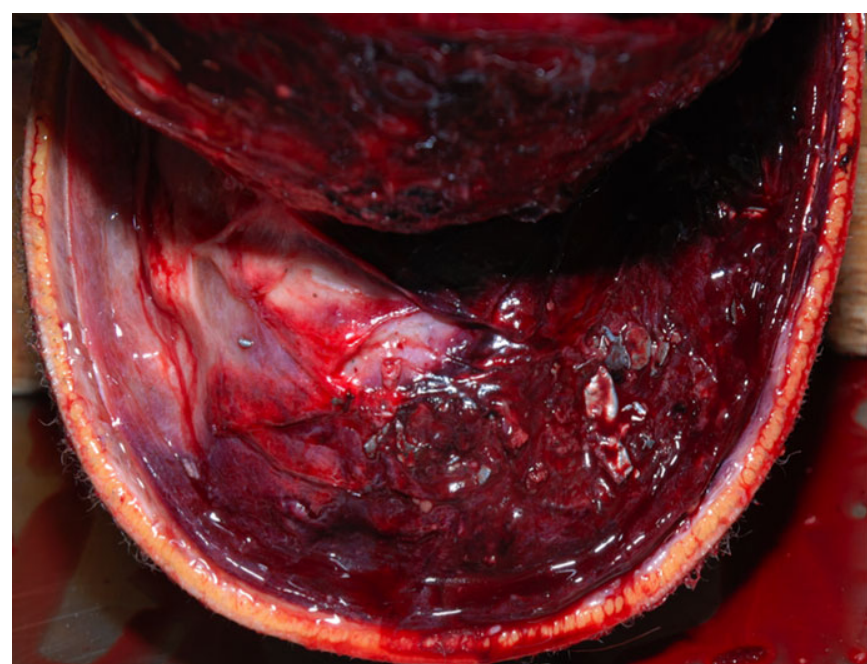

FIG. 3-Fragmented bullets recovered in the scalp adjacent to the skull.

in width, with soot deposition. The bullet fractured the skull, lacerated the temporal lobes bilaterally and the midbrain, and exited the cranial cavity. In the roof of the mouth and the hard palate (GSW \#2), there was a gunshot wound of entrance measuring $c$. 0.5 inches in diameter. The bullet perforated the palate, fractured the skull, and exited the back of the head, in the occipital region where there was a stellate-shaped gunshot wound of exit. Toxicological analyses were negative. The ability of the subject to

TABLE 2-Gunshot wounds to the head that did not penetrate the skull in case \#1.

\begin{tabular}{|c|c|c|}
\hline \# & Location & Features \\
\hline GSW \#3 & $\begin{array}{l}\text { Right side of the head, } 2.8 \text { inches beneath the top of the head, } \\
6.2 \text { inches to the right of the midline, } 1.0 \text { inch above the right ear }\end{array}$ & $\begin{array}{l}\text { Circular in shape, } 0.1 \text { inch in diameter. Concentric ring of abrasion, } \\
0.1 \text { inch in width. Lacerations were present at the } 3 \text { and } 9 \text { o'clock positions }\end{array}$ \\
\hline GSW \#4 & $\begin{array}{l}\text { Back of the head, } 2.4 \text { inches beneath the top of the head, } \\
0.6 \text { inch to the right of the posterior midline }\end{array}$ & $\begin{array}{l}\text { Circular in shape, } 0.1 \text { inch in diameter. Concentric ring of abrasion, } \\
0.1 \text { inch in width }\end{array}$ \\
\hline GSW \#5 & $\begin{array}{l}\text { Back of the head, } 2.0 \text { inches beneath the top of the head, } \\
0.2 \text { inch to the left of the posterior midline }\end{array}$ & $\begin{array}{l}\text { Circular in shape, } 0.1 \text { inch in diameter. Concentric ring of abrasion, } \\
0.15 \text { inch in width }\end{array}$ \\
\hline GSW \#6 & $\begin{array}{l}\text { Back of the head, } 4.0 \text { inches beneath the top of the head, } \\
1.4 \text { inches to the right of the posterior midline }\end{array}$ & $\begin{array}{l}\text { Circular in shape, } 0.1 \text { inch in diameter. Concentric ring of abrasion, } \\
0.1 \text { inch in width. Lacerations were present at the } 4 \text { and } 8 \text { o'clock positions }\end{array}$ \\
\hline GSW \#7 & $\begin{array}{l}\text { Back of the head, } 3.2 \text { inches beneath the top of the head, } \\
0.6 \text { inch to the right of the posterior midline }\end{array}$ & $\begin{array}{l}\text { Circular in shape, } 0.1 \text { inch in diameter. Concentric ring of abrasion, } \\
0.1 \text { inch in width }\end{array}$ \\
\hline GSW \#8 & $\begin{array}{l}\text { Back of the head, } 5.0 \text { inches beneath the top of the head, } \\
\text { in the midline }\end{array}$ & $\begin{array}{l}\text { Circular in shape, } 0.1 \text { inch in diameter. Concentric ring of abrasion, } \\
0.15 \text { inch in width. Lacerations were present at the } 1,7 \text {, and } \\
11 \text { o'clock positions }\end{array}$ \\
\hline
\end{tabular}




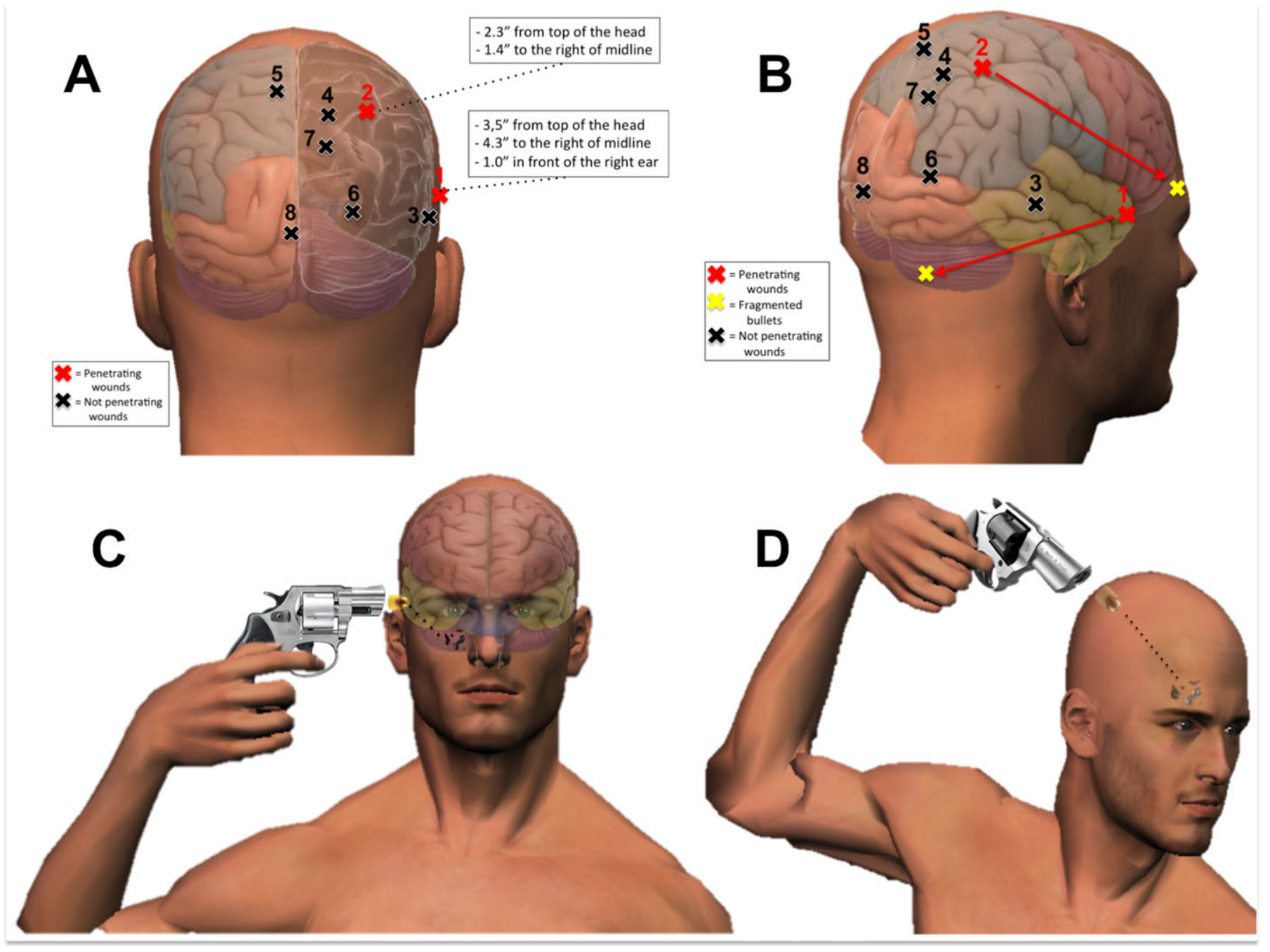

FIG. 4-Graphic reconstruction of the gunshot wounds of entrance, back (A) and lateral (B) views. Shooting dynamics reconstruction, gunshot to the right temporal scalp $(C)$; gunshot to the right parietal scalp $(D)$.

act was preserved after the first shot. The subject was pronounced at the scene.

\section{Case 4}

A 65-year-old Black man was found unresponsive on a sofa in his residence. A .38 caliber handgun was found in the subject's right hand. According to his girlfriend, the subject had complaints of excessive pain due to a prostate surgery. The subject informed his family numerous times that he was going to "kill himself" due to the "excessive pain." No suicide was found. On examination of the body, on the right temple (GSW \#1) there was a stellate-shaped gunshot wound of entrance, 0.75 inch in diameter, with soot deposition on the margins and in the underlying soft tissues. The bullet fractured the right temporal bone and exited from the left ear where there was an exit wound located close to the external auditory canal. On the submental region (GSW \#2), there was a circular gunshot wound of entrance, 1.25 inches in diameter, showing a concentric rim of abrasion and soot deposition. The bullet coursed through the mouth and the face, fractured the nasal skeleton, and perforated the frontal sinus, and a medium caliber non-jacketed lead bullet was recovered from the top of the brain within the cranial cavity.
A diffuse subarachnoid hemorrhage was present on the right side of the brain. The base of the skull revealed fractures of the right and left temporal bones and the sella turcica. Toxicological analyses were negative. The ability of the subject to act was preserved after the first shot. The subject was pronounced at the scene.

\section{Discussion}

Lethal self-inflicted gunshot wounds are most commonly sustained to the head $(81 \%)$ often in the right and left temple, followed by the mouth and submental region of the neck, the chest (17\%), particularly the precordial region, and the abdomen (2\%) $(1,2)$. However, in some instances, multiple gunshot wounds to the head are not lethal. It is a common misconception that multiple gunshot wounds to the head are invariably homicidal. Actually, further ability to act voluntarily after a gunshot can be preserved to various extents and for a relatively long time, depending on localization of the wound, damaged structures, and the physical and mental status of the victim.

The ability to act can be defined as the ability to participate in the interaction between victim and perpetrator or victim and environment, resulting in discernible events. Thus, incapacitation 
is an inability to perform complex and longer lasting movements. In this sense, incapacitation could be defined as the physical activity remaining following severe trauma until collapse. It is often relevant in legal proceedings to know whether someone who sustained injuries died immediately or became incapacitated for a while. It is important to know what type of and how long the activity was possible. The "ability to act" question is mainly discussed when multiple gunshot wounds are present. Despite multiple people suffering identical injuries, their capabilities to act could be preserved in different ways.

Incapacitation can be divided into three major groups (3): instant incapacitation, which can result from a cessation in the functioning of the central nervous system via direct disruption of brain stem tissue; rapid incapacitation, which can be achieved via massive bleeding from the heart, the thoracic aorta, the pulmonary artery, or other major veins or arteries; and delayed incapacitation, which can result from damage to other major organs, that is, the lungs, kidney, and liver. With such damage to the internal organs, total incapacitation can take a considerable period of time.

With special regard to gunshot wounds, there is a controversy due to the misconception that it is impossible to survive after one or more inflicted or self-inflicted gunshot wounds. In forensic pathology, cases in which individuals are able to perform physical activity (i.e., walk or run) prior to collapse and death, after incurring one or more fatal gunshot wounds affecting critical areas of the body are seen. Commonly, lack of immediate incapacitation may occur when a gunshot affects vital organs in the chest, such as the heart or major blood vessels. In these cases, the acute or slow blood loss may result in a period of survival and ability to act, which varies from individual to individual. According to Di Maio (4), sudden blood loss causes interference with activity when it exceeds $20-25 \%$ of the total blood supply. Loss over $40 \%$ is life-threatening. The rate of bleeding, the amount of blood loss, the nature of the injury, and the body's physiological response determine the time from injury to incapacitation and death. This can vary from seconds to hours.

Special reference needs to be made regarding the gunshot wounds to the head. Just as in the case of gunshot wounds of the heart or major blood vessels, subjects can survive or preserve ability to act when the brain is affected. If a victim becomes unable to act, this is usually due to functional impairment of the central nervous system caused either directly by tissue lesions or indirectly by insufficient oxygen supply (5). Immediate incapacitation occurs when a bullet destroyed parts of the brain essential for physical activity. Karger (6-8) explains that an individual's capacity to act following one or more gunshot wounds to the head may be due to the preservation of areas in the central nervous system referred to as "targets of immediate incapacitation." Such targets include several critical brain areas, which are essential for life support, including the upper cervical spinal cord, brainstem, cerebellum, diencephalon, and midbrain including the basal ganglia, the motor cortex, and the capsula interna. However, indirect damage of the central nervous system can be due to acute cerebral hypoxemia caused by severe blood loss; nevertheless, oxygen stored in the central nervous system ensures a potential for physical activity for about $10 \mathrm{~s}$.

Penetrating head injury due to gunshot wounds can result from both low- and high-velocity projectiles. Lower-velocity projectiles create a tract of primary tissue damage without significant bruising or blunt tearing of surrounding tissue. Highervelocity projectiles are preceded by a brief $(2 \mathrm{~ms})$ sonic shock wave, followed by the penetration of the projectile. The final damage results from the destruction of tissue in the projectile's path and also from the transmission of the bullet's kinetic energy that leads to a temporary cavitation effect. In brain tissue, which is relatively inelastic, the cavity is often 10-20 times the size of the projectile. After expansion, the cavity collapses under negative pressure that may draw in external debris. Projectiles also can deform or fragment upon striking tissue, resulting in multiple secondary missiles that cause destruction of tissues (9).

It is not necessary that the bullet passes through the targets directly, as the gunshot-related pressure and shearing forces can also damage nerve structures. Indeed, microscopic damages to the brain surrounding the bullet path can be found, demonstrating secondary effects not related to the bullet mass. These destructive changes, of different types and extent, could be detected in the tissue surrounding the permanent track. According to Oehmichen et al. (10), destruction of cells contiguous the permanent track can be explained by temporary radial acceleration and displacement of the surrounding tissue. Surrounding the permanent track, a narrow mantle-like zone of astrocyte destruction was found within an area of hemorrhagic extravasation. Some authors (11) also used a $\beta$-APP reaction to search for damage of the axons surrounding the permanent cavity, more specifically, in the immediate vicinity of the permanent cavity (ca. $2 \pm 4 \mathrm{~mm}$ ). $\beta$-APP-reacting axons and axon fragments were found, suggesting primary injured neuronal tissue by the gunshot itself (mechanical trauma). At large distances from, the permanent cavity $\beta$-APP-positive axons were arranged in two patterns. One showed conspicuous aggregates of $\beta$-APP-positive axons arrayed in parallel, wavelike arrangement of the damaged fibers, which suggested that the injury was produced by mechanical acceleration of the brain tissue created by the energy the projectile expended within the brain (expanding temporary cavity). The last pattern showed irregular aggregations of $\beta$-APP-positive axons and axon fragments arranged sometimes diagonally, sometimes longitudinally with local edema, suggesting secondary ischemia and/or to edema. According to these findings, authors concluded that the demonstration of axonal injuries may be an indication of mechanical effects on axons attributable to an expanding temporary cavity and may explain the loss of function of neurons and axonal connections in the brain stem leading to the respiratory arrest. This could explain the immediate incapacitation following the damage to a primary target in the brain.

The pathophysiological considerations described above show significant implications in cases of multiple self-inflicted gunshot wounds to the head. The preserved ability to act after a cerebral gunshot injury is observed, especially with low-energy ammunition, when the bullet itself or its track did not involve a target of immediate incapacitation. In most suicides with more than one shot to the head, only the frontal lobes or one of the temporal lobes of the brain is involved.

According to Hejna et al. (12), the ability to act can be fully preserved or only minimally limited in some circumstances. This could be when the bullet does not penetrate the cranial cavity due to the path of the missile that misses the cranial cavity, the thickness of the cranial bones that not allow the penetration of the bullet, and the nature of the weapon (e.g., low fire power); or when the bullet penetrates the cranial cavity but does not hit a critical area of the brain (such as temporal and frontal lobes of the brain).

The mechanism of incapacitation from one or more gunshot wounds may be due to the direct action of the bullet striking a critical central nervous system target, or due to the secondary 
effect of the bullet. A potential cause of death in gunshot wounds that do not affect these targets directly is the increased intracranial pressure as a consequence of the penetrating wound. As in closed head injury, intracranial pressure is likely to increase due to swelling or bleeding, potentially crushing delicate brain tissue. A rise of the intracranial pressure can be found early in a gunshot wound to the head, usually due to the massive intracranial bleeding or due to the development of secondary brain edema. In almost all gunshot wound cases involving the brain, the brain will show signs of increased intracranial pressure (such as grooves of the uncal gyri from the tentorium as well as cone-shaped molding of the cerebellar tonsils at the foramen magnum). Generally, the examination of brain shows no injuries to the vital centers by the bullet or its path. In such cases, deformation of the brain toward the foramen magnum still occurs. Pressure on the brainstem secondary to this deformation may be the fatal mechanism.

Upon a thorough review of the published literature pertaining to multiple self-inflicted gunshot wounds to the head, 81 cases document two gunshot entrance wound defects, seventeen cases document three gunshot entrance wound defects, five cases document four gunshot entrance wound defects, three cases document five gunshot entrance wound defects, and in one case reported by Lacassagne in 1906 (13), the subject shot himself seven times in the head, survived, and later committed suicide by hanging. Temporal regions were the most common afflicted regions (especially the right and left temples), followed by forehead, mouth, submental region, and cheek. A suicide note was not reported in all cases. An exhaustive summary of the literature, including weapon's model and additional features, is shown in Table S1.

In our case series, the entrance wounds were located most frequently on the temple areas and the mouth, except for case \#1 where six entrance wounds were located on the back of the head. All entrance wounds were contact or near contact wounds. Toxicological analyses were negative in all cases, in contrast to what the literature describes concerning high ethanol or illicit drugs levels in suicides $(14,15)$.

In cases \#2, \#3, and \#4, the subjects died after the second shot, like most of the cases described in the literature. In our cases, the bullets caused the disruption, directly or indirectly, of brain tissue in critical areas, such as the base of the brain and surrounding tissues. This finding may explain the rapid incapacitation of the subjects, due to damage to the targets of immediate incapacitation.

Case \#1 portrays the largest number of self-inflicted gunshot wounds to the head (8) resulting in death. In the case at hand, only two of eight small caliber projectiles entered the cranial vault. The victim was clearly not incapacitated early in the course of events as he was able to open the lockbox, while bleeding, and reload the weapon.

The excessive number of gunshot wounds and the ability to act following eight gunshot wounds to the head may have been due to several reasons. On the one hand, the fired bullets were old, unjacketed .22 short caliber, characterized by low kinetic energy. The standard velocity .22 short launches a 29-grain $(1.9 \mathrm{~g})$ bullet at 1045 feet per second $(319 \mathrm{~m} / \mathrm{s})$ with $70 \mathrm{ft} \mathrm{lbf}$ $(95 \mathrm{~J})$ of energy from a 22 in $(559 \mathrm{~mm})$ rifle barrel and can penetrate 2 inches $(51 \mathrm{~mm})$ of soft pine (16). The used weapon was a small, old revolver, devoid of high power of fire. Commonly, the majority of contact wounds with .22 short rimfire ammunition are self-inflicted wounds to the head. The small amount of powder in the cartridge and the resultant small amount of soot and gas produced result in an absence of tears at the entrance as well as very little or no deposition of soot or powder. As a result of these features, there may be problems with interpretation of the entrance wounds, because these often are mistaken for distant wounds. In these cases, only a careful examination of the wounds, together with microscopic and radiological analyses, may lead to the correct interpretation. In addition, in contact wounds of the head with the .22 short cartridge bullets, there are generally no skull fractures. If the bullet is able to penetrate the cranial cavity, it rarely exits from it, and an internal ricochet is commonly observed. The bullet usually penetrates the skull in the temporal region, where the bone tissue is thinner than the other cranial bones. Virtually in all the deaths due to .22 short rim fire ammunition, the pathologist is able to recover a fragmented or severe damaged bullet in the brain tissue.

On the other hand, the ability to act was preserved probably due to the impact of the penetrating bullet against the so-called mute areas of the brain, that is areas that are not critical. In such injuries, the usual symptomatology might be missing. The capacity to open the lockbox and reload the weapon suggests that no motor areas of the brain were affected, as well as areas of the brain involved in consciousness. Indeed, six of the eight bullets were not able to penetrate the cranial cavity because they were fired against the occipital bone, which showed an incredible resistance due to its thickness. In this case, the ability to act was probably limited only by the perception of pain due to the unpenetrated gunshots. It is impossible to establish the sequence of the shots, but most likely, the last one was the gunshot to the right temporal region, which affected the temporal lobe and the cerebellum of the brain. Despite this, the subject survived for about $22 \mathrm{~h}$, dying later in the hospital. This means that the affected areas of the brain were not the targets of immediate incapacitation or areas affecting his motor functions, as the subject had the ability to shoot himself several times.

Autopsies involving multiple gunshot wounds to the head should be approached as homicide until proven otherwise. Depending on the scene findings, clinical history, and lethality of injuries, suicide should not be excluded. Once suicide is a possible manner of death, careful attention must be paid to the brain injuries, to establish whether there was a residual ability to act. The targets of immediate incapacitation aid in understanding the dynamics of death and the degree of incapacitation. Further studies are required to clarify the dynamics of the ability to act following multiple gunshot wounds to the head, to prevent wrong conclusions concerning the circumstances and the manner of death.

\section{Acknowledgments}

The authors would like to thank Dr. Stephen J. Cina and Dr. Lauren M. Woertz for their input and discussion.

\section{References}

1. Kohlmeier RE, McMahan CA, DiMaio VJ. Suicide by firearms: a 15 year experience. Am J Forensic Med Pathol 2001;22:337-40.

2. Cina SJ, Ward M, Hopkins M, Nichols C. Multifactorial analysis of firearm wounds to the head with attention to anatomic location. Am J Forensic Med Path 1999;20:109-15.

3. Heard BJ. Multiple-shot suicides. In: Heard BJ, editor. Handbook of firearms and ballistics, examining and interpreting forensic evidence. Suicides classification of firearm-related death, 2nd edn. West Sussex, U.K.: Wiley-Blackwell, 2008;307-9. 
4. Di Maio VJM. Physical activity following gunshot wounds. In: Di Maio VJM, editor. Gunshot wounds - practical aspect of firearms, ballistics and forensic techniques. Bloody bodies and bloody scenes, 2nd edn. New York, NY: CRC Press, 1999;254-256.

5. Pollak S, Saukko PJ. Gunshot wounds. In: Jamieson A, Moenssens A, editors. Wiley encyclopedia of forensic science, Vol. 3. Chichester, U.K.: Wiley, 2009;1380-401.

6. Karger B. Penetrating gunshots to the head and lack of immediate incapacitation. Part I: I. Wound ballistics and mechanisms of incapacitation. Int J Legal Med 1995;108:53-61.

7. Karger B, Billeb E, Koops E, Brinkmann B. Autopsy features relevant for discrimination between suicidal and homicidal gunshot injuries. Int J Legal Med 2002;116:273-8.

8. Karger B, Brinkmann B. Multiple gunshot suicides: potential for physical activity and medico-legal aspects. Int J Legal Med 1997;110: $188-92$.

9. Ling GSF, Neal CJ, Ecklund JM. Management of ballistic trauma to the head. In: Brooks AJ, Clasper J, Midwinter JM, Hodgetts TJ, Mahoney PF, editors. Ryan's ballistic trauma. A practical guide, 3rd edn. London, U.K.: Springer-Verlag, 2011;323-41.

10. Oehmichen M1, Meissner C, König HG. Brain injury after gunshot wounding: morphometric analysis of cell destruction caused by temporary cavitation. J Neurotrauma 2000;17(2):155-62.

11. Oehmichen M1, Meissner C, König HG. Brain injury after survived gunshot to the head: reactive alterations at sites remote from the missile track. Forensic Sci Int 2001;115(3):189-97.

12. Hejna P, Safr M, Zátopková L. The ability to act - multiple suicidal gunshot wounds. J Forensic Leg Med 2012;19(1):1-6.

13. Lacassagne A. Précis de médecine légale [French]. Paris, France: Masson, 1906;718.
14. Varnik A, Kolves K, Vali M, Tooding LM, Wasserman D. Do alcohol restrictions reduce suicide mortality? Addiction 2007;102:251-6.

15. Kittirattanapaiboon $\mathrm{P}$, Suttajit S, Junsirimongkol B, Likhitsathian S, Srisurapanont M. Suicide risk among Thai illicit drug users with and without mental/alcohol use disorders. Neuropsychiatr Dis Treat 2014;10:453-8.

16. Barnes FC. Chapter 10: American Rimfire Cartridges Current and Obsolete in Barnes FC, Cartridges of the World: A Complete Illustrated Reference for More Than 1,500 Cartridges, 13th edn. Gun Digest Books, Inc. Krause Publications: Iola (WI) USA, 2012;e4433-39.

Additional information and reprint requests:

Lorenzo Gitto, M.D.

Department of Anatomy, Histology, Forensic Medicine and Orthopedics

"Sapienza" University of Rome

Viale Regina Elena

336, Rome 00161

Italy

E-mail: lorenzo_gitto@libero.it

\section{Supporting Information}

Additional Supporting Information may be found in the online version of this article:

Table S1. Summary of cases of suicides by multiple GSWS to the head reported in forensic literature. 